\title{
Contraceptive Knowledge, Substance Abuse and Unintended Pregnancy among First-Year Medical Students Attending a Public University in Mexico City
}

Mónica Beatriz Aburto-Arciniega ${ }^{1}$, Antonio Rafael Villa ${ }^{1}$, Angélica Arce-Cedeño ${ }^{1}$, Ricardo Antonio Escamilla-Santiago ${ }^{2}$, Claudia Díaz-Olavarrieta ${ }^{1}$, Germán Fajardo-Dolci ${ }^{1}$, Josefina Lira-Plascencia ${ }^{3}$ and Rosalinda Guevara-Guzmán ${ }^{1^{*}}$

${ }^{1}$ Research Division, School of Medicine, National Autonomous University of Mexico, Mexico

${ }^{2}$ Department of Public Health, School of Medicine, National Autonomous University of Mexico, Mexico

${ }^{3}$ National Institute of Perinatology Research Division on Adolescent Health, Mexico

*Corresponding author: Rosalinda Guevara-Guzmán, Research Division, School of Medicine, National Autonomous University of Mexico, Mexico, Tel: +525556232298; E-mail: rguevara@unam.mx

Received date: August 28, 2018; Accepted date: August 31, 2018; Published date: September 07, 2018

Copyright: (C) 2018 Aburto-Arciniega MB, et al. This is an open-access article distributed under the terms of the Creative Commons Attribution License, which permits unrestricted use, distribution, and reproduction in any medium, provided the original author and source are credited.

\begin{abstract}
Study background: Mexico is currently undergoing an adolescent pregnancy epidemic, holding the first place in teen fertility rates among countries belonging to the Organization for Economic Development and Cooperation. The country has made significant strides with national health surveys; however there is a dearth of evidence documenting the risk factors associated with adolescent pregnancy among specific groups.
\end{abstract}

Objectives: This study aims to document: knowledge, current contraceptive use and sexual practices among first-year medical students attending the largest public university in Latin America. We also measured the prevalence of unintended pregnancy and substance abuse and correlated these variables.

Methods: A convenience sample of 1,388 medical students (17-19 years) responded a survey on risk factors for unintended pregnancy. We carried out a survey's internal reliability analysis. Multivariate analysis identified variables associated with unsafe sex practices and unintended pregnancy.

Results: From the 1,388 students, $26.3 \%$ were men, 365/1,388 reported current sexual activity (in the last 3 months). Of $365,100 \%$ had heard of condoms, $71 \%$ about oral contraceptives and $76.4 \%$ considered emergency contraception an abortifacient. During their first sexual encounter, $88.2 \%$ used condoms, $3.6 \%$ used emergency contraception, $1.9 \%$ coitus interrupts, $5.8 \%$ did not use any method, $0.5 \%$ "other". $17 / 230$ women $(7.4 \%)$ became pregnant after starting their sexual life at 15 years (SD: 1.3, 3.3 mean partners, SD: 1.7). 13/17 had an abortion without specifying type and method used. Multivariate analyses showed that being sexually active, reporting current substance abuse increased the odds of unsafe sex practices and unintended pregnancy.

Conclusion: Our findings are consistent with the association of unsafe sex practices, inconsistent method use and unintended pregnancy. Our unintended pregnancy prevalence of $7.4 \%$ was lower than the national prevalence. First year medical students are primed to obtain evidence based contraceptive knowledge, correlates of unintended pregnancy, unsafe sex practices and substance abuse prevention.

Keywords: Medical students; Unintended pregnancy; Abortion; Contraceptive knowledge; Emergency contraception; Sexual behavior; Substance abuse; Mexico City

\section{Introduction}

Mexico is currently undergoing an adolescent pregnancy epidemic with fertility rates of 77 per 1,000 National Survey on Demographic Dynamics, [1] the highest of all age groups. Approximately 22 million adolescents (total population 132 million) hold the first place in teen pregnancy among countries belonging to the Organization for Economic Development and Cooperation [2].

A nationally representative 2012 survey National Survey on Health and Nutrition, [3] found that $90 \%$ of adolescents had some contraceptive knowledge, with condoms being the most commonly used method. Another national survey documented that over half of sexually active adolescents aged 12-19 years had been pregnant sometime and that sexually active adolescents aged 15-19, did not use any contraceptive method during their first sexual encounter [1].

Adolescence is a life stage characterized by physical, psychological, sexual and reproductive changes and one in which the risk for unintended pregnancy increases [4]. A study from Mexico with 3,130 adolescents between 13-19 years old reported a high prevalence of $59.5 \%$ of unintended pregnancy and identified the following risk factors: current smokers; having friends with risky health behaviors and being daughters of mothers working outside the home [5]. Studies from other countries have found an association between an early first sexual encounter without the use of a condom; using drugs and cigarettes; having multiple sexual partners or having a prior pregnancy as risk factors for unintended pregnancy $[6,7]$. 
Citation: Aburto-Arciniega MB, Villa AR, Arce-Cedeño A, Escamilla-Santiago RA, Díaz-Olavarrieta C, et al. (2018) Contraceptive Knowledge, Substance Abuse and Unintended Pregnancy among First-Year Medical Students Attending a Public University in Mexico City. J Health Educ Res Dev 6: 273. doi:10.4172/2380-5439.1000273

Page 2 of 5

In 2016, the alarming rates of teen pregnancy in Mexico led the School of Medicine at the National Autonomous University of Mexico (Universidad Nacional Autónoma de México, UNAM) to create an Adolescent Pregnancy Prevention Program (APPP) addressed to meet the gaps in evidence based contraceptive knowledge and access to effective contraceptive methods among undergraduate students as part of Mexico's federal government National Strategy to Prevent Teen Pregnancy [8]. The aims of the Adolescent Pregnancy Prevention Program and the present study were to explore the student's sociodemographic characteristics, knowledge and use of modern methods. We measured if risky sexual behaviors and substance abuse were associated with an increased probability of having unsafe sex and hence, an unintended pregnancy. The objective of this exploratory, cross-sectional study, was to document the results of an online selfadministered survey that first year medical students responded, in an effort to better understand the context in which evidence based knowledge on contraception takes place in order to decrease the risk of unintended pregnancy among college students.

\section{Materials and Methods}

\section{Data collection}

Our study was fielded among the 2016 class of first year undergraduate medical students enrolled at the National Autonomous University of Mexico (UNAM), the largest public university in the region. During orientation week, a convenience sample of male and female students aged 17-19 were approached, the study team explained the study and requested their participation answering the survey. From a total of 1,567 we approached, 1,388 were in the age range we were interested in analyzing; 17-19 years. Thus we collected survey data on $88.6 \%$ students.

\section{Ethical considerations}

The study protocol was reviewed and approved by the National Autonomous University of Mexico School of Medicine Internal Review Board. A written informed consent was signed by all 1,388 participants. The research team gave informed consent copies to all students requesting them, only students with a signed informed consent answered the survey. No compensation was given to participants.

\section{Research Instrument}

The Adolescent Pregnancy Prevention Program (APPP) team drafted an ad-hoc 68 question survey that included topics identified by students and concerns regarding contraceptive knowledge gaps, substance abuse and prevention of unintended pregnancy. These topics were selected during brief focus group discussions the research team had with enrolled medical students during the initial stages of the study. The survey included the following sections: a) Sociodemographic data; b) sexual and reproductive health topics; c) contraceptive knowledge and method use; d) current sexual history; and, d) current substance use. A pilot test was carried out to validate the survey content and questions were redrafted based on our initial findings.

\section{Statistical analysis}

We carried out an internal reliability analysis of the study survey with a Cronbach alpha test. From the 68 survey questions, we tested the 21 survey items that explained more accurately the probability of having an unintended pregnancy, being current substance users, engaging in risky sexual behaviors and knowledge of contraceptive methods. In addition, we did factor analysis to identify the factors that showed an association among sets of interrelated variables. We obtained a set of principal components.

We carried out descriptive statistics using relative frequencies (percentages). The comparison of continuous variables by sex (male vs female) was done with the Student's $t$-test. To identify factors associated with the probability of being sexually active, being current substance users and engaging in risky sexual behaviors, we tested univariate variables and built multivariate models by means of logistic regression analyses. The association measure is expressed as exponential of regression coefficients (odds ratio) with 95\% confidence intervals and p-value. All analyses were done with SPSS/PC v23.0 (IBM).

\section{Results}

\section{Demographic characteristics}

From the 1,388 students that were asked to respond to the computer based survey aged 17- 19 (mean age 18, SD: 0.6), 31.3\% were male and $68.7 \%$ female. This gender breakdown is similar to the School of Medicine's general enrolment. Almost all subjects (90.7\%) had completed high school in the National Autonomous University of Mexico public educational system. Fewer than $8 \%$ worked in addition to their course load.

\section{Sample size and reliability analysis}

Of the 1,388 medical students who responded the survey and reported ever having had sex, we analyzed 365 students who reported being currently sexually active (last 3 months). Of these 365 students, when we tested the 21 survey questions that better yielded a probability of being sexually active derived from the Cronbach alpha analysis, only 200 students who reported being currently sexually active had completed all the information included in the survey. Thus the survey's reliability analysis and the study results were based on 200 surveys that did not have missing data.

Variables tested for all the survey were selected depending on how well they explained the variability of the student's sexual behavior variance. The Cronbach's alpha value of the 21 standardized questions was 0.59 and the intra-class correlation coefficient of average measures was $0.70(95 \%, C I: 0.63-0.76)(\mathrm{p}<0.0001)$. The presence of all 21 questions was similar (approximate correlations $=0.70$ ). Our reliability values of approximately $70 \%$ may be considered as moderate for an internal consistency analysis. The analysis of main components identified eight factors that showed those variables displaying the highest probability with the highest explained variance (cumulative Eigen value $=70.0 \%$ ) in discriminating the explored sexual behaviors and that we believe were grouped in a logical and natural way (Table $1)$. 
Citation: Aburto-Arciniega MB, Villa AR, Arce-Cedeño A, Escamilla-Santiago RA, Díaz-Olavarrieta C, et al. (2018) Contraceptive Knowledge, Substance Abuse and Unintended Pregnancy among First-Year Medical Students Attending a Public University in Mexico City. J Health Educ Res Dev 6: 273. doi:10.4172/2380-5439.1000273

Page 3 of 5

\begin{tabular}{|c|c|c|c|c|c|c|c|c|}
\hline & 1 & 2 & 3 & 4 & 5 & 6 & 7 & 8 \\
\hline Have you ever been pregnant? & 0.986 & & & & & & & \\
\hline Student's sex & -0.983 & & & & & & & \\
\hline Age of the mother & & 0.907 & & & & & & \\
\hline Age of the father & & 0.897 & & & & & & \\
\hline Father's schooling & & & 0.91 & & & & & \\
\hline Mother's schooling & & & 0.894 & & & & & \\
\hline Current tobacco use & & & & 0.807 & & & & \\
\hline Current alcohol use & & & & 0.759 & & & & \\
\hline Current drug use & & & & 0.554 & & & & \\
\hline Close emotional relationship with mother & & & & & 0.757 & & & \\
\hline Close emotional relationship with father & & & & & 0.718 & & & \\
\hline Prior high school (public vs private) & & & & & & 0.821 & & \\
\hline Student's age & & & & & & 0.667 & & \\
\hline $\begin{array}{l}\text { Which is the most effective non-hormonal } \\
\text { contraceptive method to prevent a } \\
\text { pregnancy? }\end{array}$ & & & & & & & 0.794 & \\
\hline Do you know any contraceptive method? & & & & & & & 0.608 & \\
\hline Do you have a current sexual partner? & & & & & & & & 0.85 \\
\hline $\begin{array}{l}\text { What contraceptive method did you use in } \\
\text { your first sexual experience? }\end{array}$ & & & & & & & & -0.419 \\
\hline
\end{tabular}

Table 1: Rotated Component Matrix b.

\section{Sexual history and contraceptive knowledge}

Of the 1,388 students who answered the survey, 26.3\% (365) reported being currently sexually active (last 3 months). $31.1 \%$ were men (135) and $24.1 \%$ women (230). On average, age of first sexual intercourse was 16.4 years $(\mathrm{SD}=1.4)$. Among all 365 students, $100 \%$ knew about condom use, $71 \%$ knew oral contraceptives and $76.4 \%$ considered emergency contraception an abortifacient. $82 \%$ of the 365 students had used condoms during their first sexual encounter, $3.6 \%$ used emergency contraception, $1.9 \%$ coitus interrupts, $0.5 \%$ used "other" method and 5.8\% did not use any method.

Seventeen out of two hundred and thirty (7.4\%) of the currently sexually active female students reported having been pregnant once with a non-significant earlier start of sexual life (15 years SD: 1.3) compared with their non-sexually active peers (16.5 years, SD: 1.4$)$ and a mean number of 3.3 sexual partners (SD: 1.7) vs. 2 (SD: 1.5). Of these 17 women, 13 reported interrupting that pregnancy but did not specify if it was induced or spontaneous. Of the students self-defined as heterosexual who were sexually active, $80 \%$ had practiced oral and $26.6 \%$ anal sex. Twenty-two (6\%) male and female students reported homosexual intercourse, of them, $96 \%$ practiced oral and $73 \%$ anal sex.

J Health Educ Res Dev, an open access journal ISSN: $2380-5439$

\section{Substance abuse}

Among the 365 sexually active students, $45.9 \%$ male and $53.5 \%$ female students reported smoking at some point in their life, beginning, on average at 15.5 years for men and women. Current smokers (last 3 months) among sexually active students included $30.4 \%$ of male and female students with a median of two daily cigarettes. The average age at which all 365 students first tried alcohol was 15 years for both. Of the 365 sexually active students, $71.1 \%$ of men and $74.3 \%$ of women reported current alcohol use. Among both, the highest percentage consumed alcohol at least once a month $(32.6 \%$ men, $33 \%$ women). Regarding ever using drugs, $23 \%$ of males and $18.3 \%$ of females reported having consumed some type of drug; current drug users included 5.2\% males and 3.9\% females. These figures stand in comparison with national data on adolescents and young adults ever using drugs that report a consumption of $6.6 \%$ among men and 5.8\% among women [9].

\section{Multivariate analysis}

A multivariate logistic regression model found independent variables associated with the probability of being currently sexually active. As the students were older $(17+)$, the probability of sexual encounters increased $46 \%$ per year. Being male was associated with a 
Citation: Aburto-Arciniega MB, Villa AR, Arce-Cedeño A, Escamilla-Santiago RA, Díaz-Olavarrieta C, et al. (2018) Contraceptive Knowledge, Substance Abuse and Unintended Pregnancy among First-Year Medical Students Attending a Public University in Mexico City. J Health Educ Res Dev 6: 273. doi:10.4172/2380-5439.1000273

Page 4 of 5

$31 \%$ greater probability of engaging in sexual behavior compared to female students and alcohol's current consumption in male and female students increased $154 \%$, and drug consumption $174 \%$ (Table 2).

\begin{tabular}{|l|l|l|l|}
\hline Variable & OR $^{\mathrm{a}}$ & $\mathbf{9 5 \%} \mathbf{C l}$ & $\mathbf{p}$-value \\
\hline Age (yrs.) & 1.46 & $1.20-1.77$ & $<0.0001$ \\
\hline Sex (male vs female) & 1.31 & $1.01-1.71$ & 0.04 \\
\hline Current alcohol use (yes vs no) & 2.54 & $1.86-3.47$ & $<0.0001$ \\
\hline Current drug use (yes vs no) & 2.74 & $1.89-3.97$ & $<0.0001$ \\
\hline aOR=odds ratio & & & \\
\hline
\end{tabular}

Table 2: Logistic regression multivariate model to estimate the probability of being sexually active (in the last three months).

\section{Discussion}

The present study describes knowledge and use of modern contraceptive methods, sexual history (ever and in the last 3 months), unsafe sexual practices and risk behaviors (drug and alcohol use) associated with unintended pregnancy in a sample of Mexican adolescent first level entry medical students enrolled in the largest campus in Latin America. Data was collected from a self-administered computer based ad-hoc survey that included a rigorous internal reliability analysis.

In a study among Turkish undergraduate medical students, the percentage of sexually active respondents was over $50 \%$ among men and only 5\% among women [10]. Wang reported a low percentage $(10.2 \%)$ of sexually active Chinese undergraduate students and the prevalence of unintended pregnancy among them was $31.8 \%$ with $84 \%$ choosing surgical and medical abortion [11].

Mexico's national health surveys have documented that adolescents with lower academic attainment, from low socio-economic strata and limited access to medical care are those with the highest unmet need for sexuality education, comprehensive information and access to contraceptive methods [12]. This underserved population also has the highest prevalence of risk factors regarding unintended pregnancy that contribute to the country's current epidemic. While our college sample is not nationally representative due to its above average educational attainment, their knowledge and intermittent use of modern contraceptive methods is still lower than expected with a lower prevalence of unintended pregnancy compared with national data [3]. Nevertheless, there is a significant percentage that does not have the knowledge on the appropriate use of other effective contraceptive methods $[13,14]$. Our findings reveal the vulnerability and risk our medical students are exposed to an unintended pregnancy. However, their reported high condom use may serve as a protective factor against contracting sexually transmitted infections.

Thus, aside from promoting preventive and educational interventions, the National Autonomous University of Mexico Adolescent Pregnancy Prevention Program could delve deeper into the lack of evidence based knowledge of modern contraceptive method use among surveyed medical students, including misconceptions regarding consistent use and efficacy. It could also document more systematically student's type of contraceptive use and substance abuse patterns.

Campo Cabal identified that accidental or infrequent sexual intercourse, the discomfort and the couple's objection to use birth control methods are some of the reasons why medical students do not use them [15]. A study from Chile mentions a sense of invulnerability against unintended pregnancy, couple's lack of communication regarding contraceptive use, shame to ask for them at a pharmacy or doctor's office and lack of money [16]; reasons that may be similar to those of our study population.

Regarding findings from the logistic regression model, our data behaved similarly to the results of a systematic revision from Colombia, in which being older, male, smoking, using alcohol and other substances were variables associated with a history of sexual intercourse [17]. Alcohol consumption among our sample was lower to Caetano's, however our multivariate logistic regression model is similar to research where students show an increase in sexual activity and engaging in risky sex (not using a condom or having multiple partners) was coupled with substance abuse [18-20].

However, even though we did not explore substance type and consumption patterns, we documented this is a risky practice as the logistic regression model showed a greater probability of engaging in sexual encounters if both partners were using substances at the time of sexual intercourse. Our findings are in agreement with studies documenting that adolescents with substance abuse disorders report risky sexual behaviors, have multiple partners, engage in accidental sexual encounters and have a less consistent condom use [21].

Our survey's reliability analysis will inform a more comprehensive survey to measure knowledge of a wider range of contraceptive methods, risky sexual behaviors and a history of specific forms of substance abuse as correlates of unintended pregnancy.

Our study findings will allow the Adolescent Pregnancy Prevention Program team to develop an adolescent pregnancy risk factor index for medical students that will include the eight factors shown in our principal component analysis. The results will help us design targeted interventions; promote awareness and dissemination messages among students. It will also allow us to offer guidance and timely referrals to the National Autonomous University of Mexico free health care and other non-government institutions working to prevent unintended pregnancy.

Our survey high response rate will allow the Adolescent Pregnancy Prevention Program to have a more active role on campus to promote Sexual and Reproductive Health issues, prevention and promoting responsible sexual practices among future health care providers.

\section{Limitations}

A limitation of this study is the possible misinformation from survey respondents, as it is a self-administered tool. Our survey is not exhaustive and while we were able to measure some sexual behaviors among medical students, other possible lines of enquiry could include the presence of reproductive coercion while engaging in unsafe sex practices and substance abuse among students. A second limitation is that among women seeking abortions, a mixed-method study could allow us to delve deeper into this decision as Mexico City is the only state in the country that decriminalized abortion ten years ago so young female students would in fact be exercising a legal right to an elective abortion up to twelve weeks gestation.

\section{Conclusion}

The adolescent pregnancy epidemic among Mexican adolescents continues to be a challenging public health issue that prevails despite 
Citation: Aburto-Arciniega MB, Villa AR, Arce-Cedeño A, Escamilla-Santiago RA, Díaz-Olavarrieta C, et al. (2018) Contraceptive Knowledge, Substance Abuse and Unintended Pregnancy among First-Year Medical Students Attending a Public University in Mexico City. J Health Educ Res Dev 6: 273. doi:10.4172/2380-5439.1000273

Page 5 of 5

government and institutional efforts at the National Autonomous University of Mexico. The data reported among Mexican undergraduate medical students is in agreement with findings in other similar settings regarding knowledge, consistent use of contraceptive methods and high fertility rates. Our study results aimed to develop an adolescent pregnancy risk factor index for medical students that will allow us to have an algorithm that can help us identify early on at-risk students for unintended pregnancy. In our study, the prevalence of adolescents and young adults ever using drugs was significantly higher (23\% among males and $18.3 \%$ among females) compared to 2016 national data on substance abuse $(6.6 \%$ men, $5.8 \%$ women $)$ [9]. It has been documented that unsafe sex practices can lead to unintended pregnancy. As we are working with entry level students who agreed to be followed throughout their medical undergraduate years at the Faculty of Medicine, it is feasible to promote awareness of the problem and work at the group and individual level. The latter would allow us to offer contraceptive options, counseling, and timely reference to free health care and other non-government institutions dedicated to prevent unplanned pregnancy in adolescence.

An area that needs further exploration is their access to abortion services and their pathways to care. From the 17 students who reported being pregnant once, 5.6\% (13) mentioned they had interrupted their pregnancy, however, the study survey did not enquire into the method chosen even though anecdotic evidence indicates that medical abortion (misoprostol only regimen) is widely available on campus through informal networks. In our study, the research team was able to locate six women who had undergone an abortion and who agreed to participate in a focus group. From the six students we were able to reach, four agreed to be interviewed and the day of the interview only one student showed up. Other longitudinal studies on post abortion with clinic based samples in Mexico City have found similar challenges asking women to return and share their experiences. An area of research that we need to refine needs to include a strategy where women feel they can share their experiences with abortion in a safe space and not, as one of the students approached mentioned, "try to forget it ever happened".

Future studies will include a qualitative component among women who accessed an abortion and agree to participate in an in-depth interview or focus group.

\section{Acknowledgements}

The authors wish to thank the students from the School of Medicine for their willingness to participate in this research, as well as the National Autonomous University of Mexico Adolescent Pregnancy Prevention Program. Special thanks to: Vivian Phillips M.D. for her invaluable editorial help. We also wish to thank Edgar Cuauhtémoc Díaz Franco, Ph.D. from the National Institute of Perinatology, Research Division on Adolescent Health for his contributions to the study design.

\section{References}

1. National Survey on Demographic Dynamics (2014) México.
2. OECD Family Database (2009) Accessed on: August 22, 2016.

3. National Survey on Health and Nutrition (2012) México. Accessed on: May 3, 2017.

4. World Health Organization (2016) Accessed August 22, 2016.

5. Vázquez F, Vázquez $\mathrm{CF}$, Saldívar $\mathrm{AH}$, Vázquez $\mathrm{EM}$, Córdova JA, et al. (2014) Unplanned Pregnancy in Adolescents: Association with Family Structure, Employed Mother, and Female Friends with Health-Risk Habits and Behaviours. J Urban Health 91: 176-185.

6. Cao Y, Xiao H, Yan H, Li J, Li S (2015) Prevalence and sex-related risk factors of premarital pregnancy and reproductive tract infections among female undergraduates in Wuhan, China. Asia Pac J Public Health 27: 30S-40S.

7. Oulman E, Kim THM, Yunis K, Tamim H (2015) Prevalence and predictors of unintended pregnancy among women: an analysis of the Canadian Maternity Experiences Survey. BMC Pregnancy Child Birth 15: 260.

8. National Strategy on Adolescent Pregnancy Prevention (2016) Accessed on: August 22, 2016.

9. National Survey on Drug, Alcohol and Tobacco Consumption (2016) Accessed on: May 7, 2017.

10. Ozan S, Aras S, Semin S, Orcin E (2005) Sexual attitudes and behaviours among medical students in Dokuz Eylul university, Turkey. Eur J Contracept Reprod Health Care 10: 171-183.

11. Wang H, Long L, Cai H, Wu Y, Xu J, et al. (2015) Contraception and unintended pregnancy among unmarried female university students: a cross-sectional study from China. PLoS One 10: 1-11.

12. González C, Rojas R, Hernández MI, Olaiz G (2005) Profile of sexual behavior in Mexican adolescents from 12 to 19 years of age: results of the ENSA 2000. Salud Pública Mex 47: 209-218.

13. Skrzeczkowska A, Heimrath J, Surdyka J, Zalewski J (2015) Knowledge of contraceptive methods among adolescents/young adults. Pol J Publ Health 125: 144-148.

14. Kim MH (2016) Contraceptive Knowledge and Contraceptive Attitudes among University Students in Korea. Indian J Sci Technol 9: 1-8.

15. Campo-Cabal G, Becerra LV, Cedeño MC, Uribe GA, Villa LM, et al. (2006) Sexual and contraceptive behavior in medical students. Rev Colomb Psiquiatr 35: 328-340.

16. Fétis NG, Bustos ML, Lanas ZF, Baeza WB, Contreras RJ, et al. (2008) Factors associated with the use of contraceptives in high school students in the commune of Temuco. Rev Chil Obstet Ginecol 73: 362-369.

17. Campo A (2009) Sexual relationships in Colombian adolescents and the implications for public health: a review of prevalence and some associated variables. MedUNAB 12: 86-90.

18. Caetano ME, Linhares IM, Pinotti JA, Maggio da Fonseca A, Wojitani MD, et al. (2010) Sexual behaviour and knowledge of sexually transmitted infections among university students in Sao Paulo, Brazil. Int J Gynecol Obstet 110: 43-46.

19. Connor J, Psutka R, Cousins K, Gray A, Kypri K (2013) Risky drinking, risky sex: a national study of New Zealand university students. Alcohol Clin Exp Res 37: 1971-1978.

20. Aicken CR, Nardone A, Mercer CH (2010) Alcohol misuse, sexual risk behaviour and adverse sexual health outcomes: evidence from Britain's national probability sexual behaviour surveys. J Public Health 33: $262-271$

21. Sánchez ZM, Nappo SA, Cruz JI, Carlini EA, Carlini CM, et al. (2013) Sexual behaviour among high school students in Brazil: alcohol consumption and legal and illegal drug use associated with unprotected sex. Clinics 68: 489-494. 